\title{
Evaluation of Different Starches as Gelling Agents for Micropropagation of Potato
}

\author{
Winta Semere Amlesom ${ }^{1}$, Taddese Mehari ${ }^{2} \&$ Brhan Khiar Saleh ${ }^{1}$ \\ ${ }^{1}$ Hamelmalo Agricultural College, Keren, Eritrea \\ ${ }^{2}$ National Commission for Higher Education, Eritrea \\ Correspondence: Winta Semere Amlesom, Hamelmalo Agricultural College, P.O. Box 397, Keren, Eritrea. Tel: \\ 291-728-2897. E-mail: wintasem@gmail.com
}

\author{
Received: January 19, $2019 \quad$ Accepted: March 7, $2021 \quad$ Online Published: April 15, 2021 \\ doi:10.5539/jas.v13n5p144 URL: https://doi.org/10.5539/jas.v13n5p144
}

\begin{abstract}
Unavailability of clean planting material is a major constraint of potato production in Eritrea. In vitro multiplication is proved to be a reliable solution; however, due to high media cost and initial investment, its use has been limited. The current study was carried out to evaluate the effectiveness of three starches (corn, potato and barley) of both laboratory and commercial grades as agar substitute, for micropropagation of potato. Single nodes of potato were sub-cultured into a fresh modified Murashige and Skoog (MS) medium supplemented with sucrose $(3 \% \mathrm{w} / \mathrm{v})$ and gelled with $50 \mathrm{~g} / \mathrm{l}$ of six types of starches in addition to $7 \mathrm{~g} / \mathrm{l}$ of agar as a control. Gelling agents used showed a highly significant difference in all measured parameters. The $\mathrm{pH}$ of all starch based media increased by $0.23-1.3$ units during the culture time except the control media which decreased by 0.4 units. Similarly EC showed a decreasing trend in all gelling agents. In most of the measured physical parameters such as plant height, root length, fresh weight and dry weight three starch based media namely laboratory grade potato, commercial corn and laboratory corn showed better results compared to the control media. Survival of in vitro plantlets ranged between 85 and $90 \%$ after acclimatization. Both laboratory and commercial grade starch based media resulted in cost reduction of $15-22 \%$ and $61-66 \%$, respectively. This implies that using both corn and potato starches can be reliable and cost effective gelling agents for micropropagation of potato.
\end{abstract}

Keywords: Eritrea, micropropagation, starches, single node explant, MS medium

\section{Introduction}

Potato is the most important root and tuber crop in the world and is used as stable food in households, in food processing industries, alcohol production and as animal feed (Danci et al., 2012). Total world production in 2014 was approximately 370 million tons (FAO, 2015). Developing countries are now the world's biggest producers and importers of potatoes and its products, where its cultivation is expanded intensely because of its ease of cultivation and nutritional value (Lutaladio et al., 2009).

In Eritrea, potato is an integral part of the commonly grown vegetable crops. Its production is mainly in the highland areas of the country, particularly in Maekel and Debub administrative regions and limited areas in Anseba and Semenawi Keyh Bahri regions (Biniam et al., 2014b). Potato production system in Eritrea is still traditional and undeveloped (Biniam \& Tadesse, 2008). As a result, the average yield is very low (6.4 tons ha $\left.{ }^{-1}\right)$, compared to the averages for Africa (10.8 tons ha $\left.{ }^{-1}\right)$ and the world (16.8 tons ha $\left.{ }^{-1}\right)(\mathrm{FAO}, 2007)$.

Lack of efficient seed potato supply system, unavailability of improved varieties and good quality seed tuber, among others, are characteristic problems of potato production in Eritrea (Biniam et al., 2014b; Biniam \& Tadesse, 2008). Therefore, farmers use unimproved seed tuber saved from the previous season or purchased from non-reliable sources (Biniam et al., 2014a). This type of seed potato production system is characterized by low rates of multiplication and carry high risk of disease infection (Tadesse, 2000). Biniam and Tadesse (2008) reported detection of five of the six most important potato viruses (PVX, PVY, PLRV, PVS and PVA), in single and multiple infections. As a consequence the unavailability of standard seed supply systems coupled with disease and virus infection causes the overall potato yield losses in Eritrea.

One of the promising solutions to potato production constraints in Eritrea is to provide high yielding, improved quality and disease free seeds through the application of tissue culture technology. However, high production 
cost has been an impediment to tissue culture adoption. One of the factors contributing to the high cost of production is the cost of culture nutrient media which requires several chemicals that are often very expensive. Gelling agents such as agar constitute about $70 \%$ of the total cost (Purohit et al., 2011). Therefore, a quest for an alternative to agar as gelling agent will result in significant reduction of cost of tissue culture propagated seed potato material.

Agar has been the choice in the majority of tissue culture systems as it assures adequate support and translocation of water and mineral nutrients to explants (Ivanova \& Van Staden, 2011). Thus it is very crucial that alternative gelling agents need not only be economical; but also of satisfactory qualities.

Several alternative gelling agents, such as corn starch, barley starch, white flour, laundry starch, semolina, potato starch, rice powder, sago, sweet potato, maize, rice, wheat, sorghum and cassava have been proposed since the 1980s (Sorvari, 1986a, 1986b, 1986c, Henderson \& Kinnersley, 1988, Ullah et al., 2015; Teixeira da Silva, 2015). The current study was, thus, designed to assess the effectiveness of some starches (potato, barley and corn of commercial and laboratory grades) as substitute gelling agents for agar in the micro-propagation of potato.

\section{Materials and Methods}

\subsection{Planting Material and Experimental Design}

This study was conducted in the Tissue Culture Laboratory of the National Agricultural Research Institute (NARI) at Halhale, Eritrea. Single-node explants from previously maintained disease and virus free plantlets of variety Kufri Chipsona-3 cultured in Gelrite gelatinized media was used as planting material for carrying out the experiment.

Six different starch sources, in addition to agar as a control, were accommodated in a complete randomized design (CRD). Each treatment had 10 replicate test-tubes, each containing a single-node ex-plant.

\subsection{Media Preparation}

The MS medium including modified Vitamins (4.41 g/l) supplemented with sucrose $30 \mathrm{~g} / \mathrm{l}$ and $2 \mathrm{mg} / \mathrm{l} \mathrm{D}$-calcium pantothenate was used. Then MS medium was supplemented with agar $7 \mathrm{~g} / \mathrm{l}$ as a control and the six starch sources barley, potato and corn (commercial and laboratory grades each) were added at a rate of $50 \mathrm{~g} / \mathrm{l}$. The rates of potato and corn starches were decided based on Mohamed et al. (2010), while for barley starch Sorvari (1986b) was followed. Prior to autoclaving the $\mathrm{pH}$ of the medium was adjusted to 5.7.

Gelatinization of the nutrient medium was made by mixing the starch with cold distilled water and pouring the mixture slowly into hot $\left(>95{ }^{\circ} \mathrm{C}\right)$ nutrient medium and mixing continuously. Then $10 \mathrm{ml}$ of the gelatinized medium was poured in each test tube. Due to the soft texture of barley commercial and barley laboratory media, polyester nets were used to prevent sinking of the cultures. Following that, the nutrient media were covered and autoclaved at $121{ }^{\circ} \mathrm{C}$ for $21 \mathrm{~min}$ under $1.5 \mathrm{KPa}$ pressure.

\subsection{Inoculation and Multiplication}

The single node explants were excised essentially from middle nodes of the microplants for maintaining explants' homogeneity. The test tubes were sealed with Para-film tagged with the corresponding line number and date of subculture. They were then incubated at $21 \pm 1{ }^{\circ} \mathrm{C}$ under a $16 \mathrm{~h}$ photoperiod with a photosynthetic photon flux density of $40 \mu \mathrm{mol} \mathrm{m}{ }^{-2} \mathrm{~s}^{-1}$ provided by overhead cool fluorescent lamps (Philips, India 30 Watts) and humidity range of $50-60 \%$, for 28 days in a culture room.

Multiplication was carried out through sub-culturing the explants at 4 weeks interval, and each treatment was sub-cultured into its respective media type. This was done to confirm the starch capabilities of supporting the plant and to evaluate the effect of the starch in subsequent sub-cultures (generations).

\subsection{Acclimatization of Plantlets}

Seven plantlets of each treatment with well-developed root and shoot systems were washed with tap water and transplanted into acclimatization trays filled with a soil mix of sand, clay and compost in a ratio of 2:1:1. The trays with plantlets were then kept in an acclimatization chamber for 21 days. Afterwards the plants were transferred into pots and evaluated by counting the number of live plants.

\subsection{Data Collection and Analysis}

Twenty-eight days after culturing, three culture tubes each with one microplant from each treatment were randomly picked for data collection. Then observations on plantlet height, root length, number of leaves, plantlet fresh and dry weights were recorded and averaged. 
The three media were homogenized individually after removing the plantlets then, the $\mathrm{pH}$ and $\mathrm{EC}$ were measured with Systronics 362 digital $\mu \mathrm{pH}$ meter and Jenway Conductivity meter 4150 (UK), respectively.

GENSTAT Discovery edition 4, statistical software (VSN international) was used for data analysis. The data was subject to the analysis of variance and least significant difference at $\mathrm{P} \leq 0.05$ was used to separate the difference between treatment means.

\subsection{Cost Comparison of Gelling Agents}

The cost of media with different gelling agents was computed based on the prices of media that were prevailing at the time of their use during the period of experimentation (2015/2016). The percentage cost reduction was calculated using the following formulae:

$$
\text { Cost reduction }(\%)=\frac{\text { Cost of Agargelled Media }- \text { Cost of Alternative Media }}{\text { Cost of Agargelled Media }} \times 100
$$

\section{Results and Discussion}

\subsection{Gel State and Clarity}

The control treatment, agar, formed a solid and transparent media. While the alternative gelling agents showed either a semi-solid or semi-liquid gel state and were either semi-opaque or opaque in clarity. The media state is an important aspect of a gelling agent in supporting a plantlet from sinking, while gel clarity is vital in detecting microbial contamination.

Table 1. Media state and clarity of the different gelling agents

\begin{tabular}{lll}
\hline Treatments & Gel state & Gel clarity \\
\hline Agar & Solid & Transparent \\
Corn laboratory & Semi-Solid & Opaque \\
Potato laboratory & Semi-Solid & Transparent \\
Barley laboratory & Semi-Liquid & Semi-Opaque \\
Corn commercial & Semi-Solid & Opaque \\
Potato commercial & Semi-Solid & Opaque \\
Barley commercial & Semi-Liquid & Opaque \\
\hline
\end{tabular}

\subsection{Effect on $E C$ and $p H$}

After autoclaving the media, the Electrical Conductivity (EC) and $\mathrm{pH}$ of the different gelling agents was variable (Table 2). The EC ranged between 4.51 Millisiemns/cm (corn LG) and 6.17 (barley LG).While media pH showed a decrease from the adjusted $5.7 \mathrm{pH}$ in all treatments except potato $\mathrm{LG}$.

The results in Table 2 show that the difference on media EC and $\mathrm{pH}$ measured four weeks after culturing was significantly different $(\mathrm{p}<0.01)$ among the seven gelling agents. The highest $\mathrm{EC}$ was recorded in barley LG gelled media (5.77 Millisiemns/cm) and corn LG showed the lowest (4.13Millisiemns $/ \mathrm{cm})$. While the highest $\mathrm{pH}$ was recorded in corn LG gelled media (6.12) compared to agar which showed the lowest result (4.92). The variation in $\mathrm{pH}$ and $\mathrm{EC}$ could be mainly due to ionic composition of the different gelling agents. Dougall (1980) attributed changes in $\mathrm{pH}$ to the ammonium $\left(\mathrm{NH}_{4}\right)$ and nitrate $\left(\mathrm{NO}_{3}\right)$ uptake by in vitro grown tissue which is affected by the initial $\mathrm{pH}$ of the medium. In agreement with Skirvin et al. (1986) agar gelled media of the current study showed a reduction in $\mathrm{pH}$, while the starch based alternative gelling agents showed increased $\mathrm{pH}$ levels. This can be attributed to the presence of different chemical composition in the various media which creates variable amounts of $\mathrm{H}^{+}$and $\mathrm{OH}^{-}$.

Media $\mathrm{pH}$ may affect the auxin and gibberellic acid stability, precipitate phosphate and iron salts and vitamin B1 and pantothenic acid to become less (Skirvin et al., 1986). Since in the current study the alternative media showed increase in $\mathrm{pH}$, those negative effects might have been reduced. 
Table 2. EC and $\mathrm{pH}$ of the different gelling agents before culturing and four weeks after culture

\begin{tabular}{lllll}
\hline Treatment & EC Before culturing & EC 4 weeks After & $\mathrm{pH}$ Before culturing & $\mathrm{pH} 4$ weeks After \\
\hline Agar & 5.52 & 4.808 & 5.34 & 4.916 \\
Corn LG & 4.52 & 4.133 & 4.85 & 6.117 \\
Potato LG & 4.80 & 4.333 & 5.69 & 5.953 \\
Barley LG & 6.12 & 5.773 & 4.71 & 5.897 \\
Corn CG & 4.58 & 4.387 & 4.76 & 5.687 \\
Potato CG & 4.64 & 4.517 & 4.82 & 5.580 \\
Barley CG & 5.54 & 5.481 & 4.69 & 5.537 \\
LSD (5\%) & & 0.3718 & & 0.3545 \\
CV\% & 8.2 & & 6.6
\end{tabular}

Note. $\mathrm{LG}=$ Laboratory grade; $\mathrm{CG}=$ Commercial grade.

The chemical parameters of the culture medium could lead to undesirable effects on plant growth and nutrient element availability. The highest EC recorded in both commercial and laboratory grade barley might have caused low nutrient element availability, poor plant growth, and nutrient element imbalance (Shibli et al., 1999). This is in agreement with the poor physical performance of both barley starch grades of the current study. This result is also in agreement with that of Shatnawi et al. (2010) where the number of shoots, number of new leaves, fresh weight and dry weight decreased with increasing salt content in the medium.

\subsection{Growth Parameters}

The results in Table 3 shows the difference among treatments in all growth parameters (plant height, number of leaves/plant, root length and fresh and dry weight) was significant $(\mathrm{P}<0.05)$. Similarly the difference among the three generations and the interaction between the treatments and generations was significant $(\mathrm{P}<0.05)$.

\subsubsection{Effect of Gelling Agenton Plant Height}

The highest plant height was recorded in media gelled with potato LG $(11.56 \mathrm{~cm})$, while the lowest was recorded in media gelled with barley LG $(4.91 \mathrm{~cm})$. Potato LG, corn LG and corn CG, gelled media showed better results as compared to the control. These results are in agreement with those of Mohamed et al. (2010), where corn starch and potato starch gelled media showed higher plant height values as compared to the control (Agar). The reason could possibly lie in the nature, consistency and rigidity of the different media which are dependent on the gelling agent used. Moreover, the better response in starch gelled media could also be due to the absence of inhibitors which have been reported to be present in agar (Puchooa \& Purseramen, 1999).

Barley LG generally showed lower plant height levels in comparison with the other gelling agents and the possible reason for this could be explained by earlier findings of Dobraski et al. (2011) where the rheological and diffusion properties of gelling agents affected shoot development in apple and black locus. In addition to that the saline conditions in the media gelled with barley can also be another possible reason. Shibli et al. (1999) found that when salinity increases significantly with time, low nutrient element availability, poor plant growth, and nutrient element imbalance are expected. This might be due to the greater osmotic stress and ionic contamination which would have decreased the optimum growth as reported in banana under in vitro conditions (Gebre \& Sathyanarayana, 2001). 
Table 3. Effect of gelling agent on plant physical parameters

\begin{tabular}{|c|c|c|c|c|c|c|c|c|c|c|c|c|}
\hline \multirow{2}{*}{ Treatment } & \multicolumn{4}{|c|}{ Plant Height $(\mathrm{cm})$} & \multicolumn{4}{|c|}{ Leaf Number } & \multicolumn{4}{|c|}{ Root Length $(\mathrm{cm})$} \\
\hline & G1 & G2 & G3 & Mean & G1 & G2 & G3 & Mean & G1 & G2 & G3 & Mean \\
\hline Agar & 10.20 & 10.00 & 8.73 & 9.64 & 14.00 & 11.00 & 12 & 12.33 & 7.40 & 4.83 & 6.40 & 6.21 \\
\hline Corn LG & 10.20 & 14.37 & 8.67 & 11.08 & 10.33 & 12.00 & 10.33 & 10.89 & 4.93 & 5.18 & 5.00 & 5.04 \\
\hline Potato LG & 13.67 & 10.83 & 10.17 & 11.56 & 9.67 & 11.00 & 10.67 & 10.45 & 6.67 & 6.90 & 5.8 & 6.46 \\
\hline Barley LG & 4.07 & 4.83 & 5.83 & 4.91 & 10.67 & 7.67 & 6.33 & 8.22 & 2.77 & 5.6 & 1.6 & 3.32 \\
\hline Corn CG & 10.17 & 11.77 & 8.77 & 10.24 & 12.67 & 10.00 & 11.67 & 11.45 & 7.77 & 5.07 & 9.33 & 7.39 \\
\hline Potato CG & 7.27 & 10.80 & 6.90 & 8.32 & 10.00 & 11.67 & 10.33 & 10.67 & 5.57 & 8.50 & 8.40 & 7.49 \\
\hline Barley CG & 9.50 & 6.30 & 7.20 & 7.67 & 10.00 & 9.67 & 9.00 & 9.56 & 3.67 & 5.8 & 3.93 & 4.47 \\
\hline Mean & $9.30^{*}$ & $9.84 *$ & $8.04^{*}$ & $9.06^{*}$ & $11.05^{*}$ & $10.43^{*}$ & $10.05^{*}$ & $10.51 *$ & $5.54 \%$ & $5.98 *$ & $5.78^{*}$ & $5.98^{*}$ \\
\hline $\operatorname{LSD}(5 \%)$ & 2.9 & 2.96 & 2.20 & 1.5 & 2.51 & 1.62 & 1.83 & 1.122 & 0.65 & 0.65 & 0.73 & 0.37 \\
\hline $\mathrm{CV} \%$ & 17.8 & 17.1 & 15.6 & 17.4 & 13 & 8.9 & 10.4 & 10.77 & 6.7 & 6.2 & 7.2 & 6.7 \\
\hline
\end{tabular}

Note. $\mathrm{LG}=$ Laboratory grade; $\mathrm{CG}=$ Commercial grade.

\subsubsection{Effect of Gelling Agent on Number of Leaves}

The highest number of leaves per explant was 12.33 recorded in agar media, while barley CG performed the poorest of all the treatments with average leaf numbers of 8.22 (Table 3). These results are contrary to those of Mohamed et al. (2010) who found highest number of shoots/explant in medium gelled with potato starch. The lowest value was recorded in barley LG. The possible reason for this low performance of barley in the current study might be in the contents of the barley starch used in the current study which seems to contain compounds that might have interacted with the plant nutrient uptake activity negatively and further inhibited the differentiation of plantlets, but it is unclear if those compounds are similar to the impurities found in agar. Another possible reason might be the high salinity in the media (Table 2) recorded before inoculation of the plant that might have severely affected nutrient uptake of the plant from the media and hence caused ill effects on the plant's physiological development. Another study reported by Batty and Dunwell (1989), showed that potato anthers cultured on a medium containing maltose produced significantly fewer embryos than those cultured on sucrose. Therefore, the presence of maltose in barley LG may have inhibitory effects.

\subsubsection{Effect of Gelling Agent on Root Length}

The performance of agar was lower compared to starches of commercial grade of potato $(7.49 \mathrm{~cm})$ and corn $(7.39 \mathrm{~cm})$ as well as potato LG $(6.46 \mathrm{~cm})$, while barley LG $(3.32 \mathrm{~cm})$ and barley CG $(4.47 \mathrm{~cm})$ had shorter root length compared to all gelling agents including the control agar (Table 3). Scholten and Pierik (1998) inferred that agar could have a number of drawbacks that could negatively affect morphogenesis and culture growth in some plants. In addition to that, toxic exudates from the cultured explants may take longer time to diffuse (Powell \& Uhrig, 1987) since agar is more solid. The increase in number of roots and root length in the starches might be due to the low viscosity of the media, better availability of water and nutrients and closer contact between explants and the medium than in the media solidified with agar.

Mellor and Stace-Smith (1969) found the rooting of excised potato buds to be best at $\mathrm{pH} 5.7$, root formation being inhibited at $\mathrm{pH}$ levels of 4.8 and 6.2 or above. However, in the current study, the effect of $\mathrm{pH}$ on rooting might have not been clearly influenced by $\mathrm{pH}$ levels where the $\mathrm{pH}$ of barley starch that recorded the lowest root length was similar to the $\mathrm{pH}$ of potato and corn starch gelled media that recorded the two highest root lengths (Tables 2 and 3). On the other hand Shibli et al. (1999) related high media EC with low nutrient availability, poor plant growth, and nutrient element imbalance. This is in agreement with the results of the current study where barley gelled media had the highest EC but lowest root length (Tables 2 and 3) compared to the rest of the gelling agents.

\subsubsection{Effectof Gelling Agent on Fresh and Dry Weight}

The highest average fresh weight was recorded in potato LG gelled media $(0.28 \mathrm{~g})$ followed by corn LG $(0.264$ $\mathrm{g})$, while the lowest average was obtained from barley LG $(0.13 \mathrm{~g})$ followed by barley CG which recorded an average fresh weight of $0.15 \mathrm{~g}$ (Table 4). This result is in agreement with the findings of Mohamed et al. (2010) where plantlets developed on media with corn starch or potato starch had higher shoot fresh weight.The possible reason for the poor performance of the plants in barley could be due to the presence of impurities in their content that could have triggered negative interaction with the plants.

Compared to agar which recorded a dry weight of $0.019 \mathrm{~g}$, the highest average dry weight was recorded by media gelled with corn CG $(0.021 \mathrm{~g})$, whereas the lowest average $(0.012 \mathrm{~g})$ was recorded by media gelled with 
barley LG (Table 4). The result of corn starch is in agreement with the findings of Mohamed et al. (2010) who found corn starch to have significantly higher dry weight than agar.

In another study, Henderson and Kinnersely (1988) found similar results in using corn starch as agar alternative for wild carrot and tobacco cell cultures, in which cell dry weight increased more than three times with respect to cells grown in a medium gelled with agar. Similar results were also obtained by Sharma et al. (2011) who observed different potato varieties including Kufri-Chipsona-3, developed on media with $7 \mathrm{~g} / \mathrm{l}$ of agar had less dry weight compared to those grown in medium with agar-alternative. The possible reasons could be due to the contribution of nutritional contents present in the corn starch used such as vitamin B-complex including B1 (thiamine), B2 (niacin), B3 (riboflavin), B5 (pantothenic acid) and B6, carbohydrates, protein in small amount and can easily be taken by the plant (Kumar \& Jhariya, 2013). Similar to the fresh weight values, barley LG and barley CG showed the lowest dry weight values. This might be caused by the salinity of the media under which low nutrient elements availability, poor plant growth, and nutrient element imbalance are expected (Shibli et al., 1999).

Table 4. Effect of gelling agent on wet and dry weight

\begin{tabular}{|c|c|c|c|c|c|c|c|c|}
\hline \multirow{2}{*}{ Treatment } & \multicolumn{4}{|c|}{ Fresh weight (mg) } & \multicolumn{4}{|c|}{ Dry weight (mg) } \\
\hline & G1 & $\mathrm{G} 2$ & G3 & Mean & G1 & $\mathrm{G} 2$ & G3 & Mean \\
\hline Agar & 0.333 & 0.249 & 0.203 & 0.2617 & 0.0210 & 0.0210 & 0.0140 & 0.01867 \\
\hline Corn LG & 0.22 & 0.4 & 0.171 & 0.2637 & 0.0170 & 0.0270 & 0.0143 & 0.01944 \\
\hline Potato LG & 0.315 & 0.318 & 0.203 & 0.2787 & 0.0180 & 0.0260 & 0.0133 & 0.01911 \\
\hline Barley LG & 0.107 & 0.191 & 0.1 & 0.1327 & 0.0130 & 0.0170 & 0.0083 & 0.01278 \\
\hline Corn CG & 0.268 & 0.281 & 0.237 & 0.262 & 0.0250 & 0.0200 & 0.0183 & 0.02111 \\
\hline Potato CG & 0.191 & 0.317 & 0.138 & 0.2153 & 0.0100 & 0.0250 & 0.0133 & 0.01611 \\
\hline Barley CG & 0.159 & 0.153 & 0.143 & 0.1517 & 0.0120 & 0.0130 & 0.0103 & 0.01178 \\
\hline Mean & 0.2276 & 0.2727 & 0.1707 & 0.2237 & 0.0166 & 0.0213 & .01314 & 0.01700 \\
\hline $\operatorname{LSD}(5 \%)$ & 0.03065 & 0.02648 & 0.03502 & 0.02909 & 0.003034 & 0.005694 & 0.7305 & 0.00430 \\
\hline $\mathrm{CV} \%$ & 7.7 & 5.5 & 11.7 & 7.9 & 10.5 & 15.3 & 7.2 & 15.4 \\
\hline
\end{tabular}

Note. $\mathrm{LG}=$ Laboratory grade; $\mathrm{CG}=$ Commercial grade.

\subsubsection{Generation Effect}

In most of the results obtained from plant physical parameters (Tables 3 and 4), the highest performance was recorded in the second generation except for leaf number. First and third generations showed relatively lower performance in comparison with the second generation. The possible reason for this could be the fact that in the first generation the plantlets were transferred from a gelrite gelled media to the different gelling agents that were used in the current study. Therefore, the plantlets might have faced a possible shock and might have used that stage as an adjustment stage. In case of the third generation the results showed reduction and this is a usual phenomenon in tissue culture since the plant is manipulated with every subculture and as a result reduction in performance of the plant is expected in subsequent generations. This is in agreement with the findings of Madege et al. (2015) who found significant difference between different gelling agents and subsequent generations.

\subsection{Survival Percentage}

When plantlets were transferred from in vitro to external conditions for the purpose of acclimatization; the survival rate was generally high with all gelling agents. The percentage ranged between 85 and $90 \%$. The highest results were obtained in plantlets that were grown in media gelled with corn CG and potato LG. While the survival percentage of plantlets from all the media gelled with the rest of starches and agar recorded a survival percentage of $85 \%$. Since plantlets were grown previously in vitro under controlled environment of temperature, light and humidity some anatomical and morphological changes could be induced in plantlets. Consequently, transferring to harsh conditions may result in death of some of these plantlets.

\subsection{Cost Analysis}

Cost analysis has been done to observe the cost of each starch media compared to the control. According to the cost analysis conducted, agar was very high compared to all types of starches used. Similarly the cost of the 
laboratory grade starches was more expensive compared to the commercial grades of starches bought from super markets.

The cost of agar per litre of media is $38.5 \mathrm{Nakfa}$ (local currency). However, substituting agar with alternative starches showed a significant reduction in the cost of tissue culture media. The highest cost reduction was observed in media gelled with barley and potato commercial starches $(66 \%)$, while the lowest cost reduction was recorded in laboratory starches of both corn and potato (15\%) (Table 4).

Table 5. Cost reduction (in Nakfa) for the different gelling agents compared to agar

\begin{tabular}{|c|c|c|c|c|c|c|}
\hline \multirow{2}{*}{ Gelling Agent } & \multirow{2}{*}{ Price/Kg } & \multirow{2}{*}{ Conc. $(\mathrm{g} / \mathrm{l})$} & \multicolumn{2}{|c|}{ Cost $/ 1$} & \multirow{2}{*}{ Cost of media/l } & \multirow{2}{*}{ Cost reduction $(\%)$} \\
\hline & & & Gelling agent & Other ingrid & & \\
\hline Agar & 5500.00 & 7 & 38.50 & 16.50 & 55.00 & - \\
\hline Corn laboratory & 607.50 & 50 & 30.40 & 16.50 & 46.90 & 15 \\
\hline Potato laboratory & 607.50 & 50 & 30.40 & 16.50 & 46.90 & 15 \\
\hline Barley laboratory & 526.50 & 50 & 26.30 & 16.50 & 42.80 & 22 \\
\hline Corn commercial & 100.00 & 50 & 5.00 & 16.50 & 21.50 & 61 \\
\hline Potato commercial & 45.90 & 50 & 2.30 & 16.50 & 18.80 & 66 \\
\hline Barley commercial & 42.50 & 50 & 2.10 & 16.50 & 18.60 & 66 \\
\hline
\end{tabular}

Note. 1 USD $=15$ Nakfa.

\section{Conclusion}

The results of this study suggest that using corn and potato starches at $50 \mathrm{~g} / \mathrm{l}$ as solidifying agent instead of agar can be efficient and cost effective for single node potato micropropagation. While both commercial and laboratory grades of barley were not satisfactory for micropropagation of potato.

\section{Acknowledgements}

The authors would like to appreciate Hamelmalo Agricultural College (HAC) for funding the research and National Agricultural Research Institute (NARI) for providing laboratory access as well as technical and material assistance during the research.

\section{References}

Batty, N., \& Dunwell, J. (1989). Effect of maltose on the response of potato anthers in culture. Plant Cell Tissue Organ Culture, 18, 221-226. https://doi.org/10.1007/BF00047748

Biniam, M. G., Githiri, S. M., Tadesse, M., \& Remmy, W. K. (2014a). Potato Seed Supply, Marketing and Production Constraints in Eritrea. American Journal of Plant Sciences, 5, 3684-3693. https://doi.org/ 10.4236/ajps.2014.524384

Biniam, M. G., Githiri, S. M., Tadesse, M., \& Remmy, W. K. (2014b). Diagnostic survey on potato production practices in Eritrea. ARPN (Asian Research Publishing Network) Journal of Agricultural and Biological Science, 9(12).

Biniam, T., \& Tadesse, M. (2008). A survey of viral status on potatoes grown in Eritrea and in vitro virus elimination of a local variety 'Tsaeda embaba'. African Journal of Biotechnology, 7(4), 397-403.

Danci, M., Danci, O., Mike, L., Baciu, A., Olaru, D., Petolescu, C., ... David, I. (2012). Production of virus free potato plantlets. Journal of Horticulture, Forestry and Biotechnology, 16(1), 232-238.

Dougall, D. K. (1980). Nutrition and metabolism. In E. J. Staba (Ed.), Plant Tissue Cultures and Source of Biochemicals (pp. 21-58). Chemical Huibber Company Press, Boca Raton, FL.

FAO (Food and Agriculture Organization of the United Nations). (2015). FAOSTAT. FAO, Rome.

Gebre, E., \& Sathyanarayana, B. N. (2001). Tapioca . A new and cheaper alternative to agar for direct microtuber production from nodal culture of potato. African Crop Science Journal, 9, 1-8. https://doi.org/10.4314/ acsj.v9i1.27618

Henderson, W. E., \& Kinnersley, A. M. (1988). Corn starch as an alternative gelling agent for plant tissue culture. Plant Cell and Tissue Organs Culture, 15, 17-22. https://doi.org/10.1007/BF00039885 
Ivanova, M., \&Van, S. J. (2011). Influence of gelling agent and cytokinins on the control of hyperhydricity in Aloe polyphylla. Plant Cell Tissue and Organ Culture, 104, 13-21. https://doi.org/10.1007/s11240-0109794-5

Kumar, D., \& Jhariya, A. N. (2013). Nutritional, Medicinal and Economical importance of Corn: A Mini Review. Research Journal of Pharmaceutical Sciences, 2(7), 7-8.

Kuria, P., Demo, P., Nyende, A., \& Kahangi, E. (2008). Cassava starch as an alternative cheap gelling agent for the in vitro micro-propagation of potato (Solanum tuberosum L.). African Journal of Biotechnology, 7(3), 301-307.

Lutaladio, N., Ortiz, O., Haverkort, A., \& Caldiz, D. (2009). Sustainable Potato Production: Guidelines for Developing Countries. FAO, Rome.

Madege, R., Mneney, E., Misangu, R., \& Maerere, A. (2015). Characterization of botanical starches as a potential substitutes of agar in tissue culture media. African Journal of Biotechnology, 14(8), 702-713. https://doi.org/10.5897/AJB2014.14289

Mellor, F. C., \& Stace-Smith, R. (1969). Development of excised potato buds in nutrient medium. Can. J. Bot., 47, 1617-1621. https://doi.org/10.1139/b69-232

Mohamed, M. A. H., Alsadon, A. A., \& Al Mohaidib, M. S. (2010). Corn and potato starch as an alternative for Solanum tuberosum micropropagation. African Journal of Biotechnology, 9(1), 012-016.

Powell, W., \& Uhrig, H. (1987). Anther culture of Solanum genotypes. Plant Cell Tissue and Organ Culture, 11, 13-24. https://doi.org/10.1007/BF00036572

Puchooa, D., \& Purseramen, R. (1999). Effects of medium support and gelling agent in tissue culture of tobacco (Nicotiana tabacum). Sci. Technol. Res. J., 3, 129-144.

Purohit, S. D., Teixeira da Silva, J. A., \& Habibi, N. (2011). Current Approaches for Cheaper and Better Micropropagation Technologies. International Journal of Plant Development Biology, 5(1), 1-36.

Scholten, H. J., \& Pierik, R. L. M. (1998). Agar as a gelling agent: chemical and physical analysis. Plant Cell Rep., 17, 230-235. https://doi.org/10.1007/s002990050384

Shatnawi, M., Al-Fauri, A., Megdadib, H., Al-Shatnawic, M. K., Saead, R. S., Rommana, A., \& Al-Ghzawi, A. (2010). In vitro multiplication of Chrysanthemum morifolium Ramat and it is Responses to $\mathrm{NaCl}$ Induced Salinity. Jordan Journal of Biological Sciences, 3(3), 101-110.

Shibli, R. A., Mohammad, M. J., Ajlouni, M. M., Shatnawi, M. A., \& Obeidat, A. F. (1999). Stability of chemical parameters of tissue culture medium $(\mathrm{pH}$, osmolarity, electrical conductivity) as a function of time of growth. Journal of Plant Nutrition, 22(3), 501-510. https://doi.org/10.1080/01904169909365647

Skirvin, R. M., Chu, M. C., Mann, M. L., Young, H., Sullivan, J., \& Fermanian, T. (1986). Stability of tissue culture medium $\mathrm{pH}$ as a function of autoclaving time and cultured plant material. Plant Cell Rep., 5, 292-297. https://doi.org/10.1007/BF00269825

Sorvari, S. (1986a). The effect of starch gelatinized nutrient media in barley anther cultures. Annales Agriculturae Fenniae, 25, 127-133.

Sorvari, S. (1986b). Differentiation of potato tuber discs in barley starch gelatinized nutrient media. Annales Agriculturae Fenniae, 25, 135-138.

Sorvari, S. (1986c). Comparison of anther cultures of barley cultivars in barley-starch and agar gelatinized media. Annales Agriculturae Fenniae, 25, 249-254.

Tadesse, M. (2000). Manipulating the physiological quality of in vitro plantlets and transplants of potato (PhD Thesis, Wageningen University, The Netherlands).

Teixeira da Silva, J. A. (2015). Response of Syngonium podophyllum L. 'White Butterfly' shoot cultures to alternative media additives and gelling agents, and flow cytometric analysis of regenerants. Nusantara Bioscience, 7(1), 26-32. https://doi.org/10.13057/nusbiosci/n070105

Ullah, M. A., Uddin, M. I., Puteh, A. B., Haque, M. S., \& Islam, M. S. (2015). Alternative Gelling Agents for in vitro propagation of orchid (Dendrobiumsonia). Journal of Animal and Plant Sciences, 25(3), 792-797. 


\section{Copyrights}

Copyright for this article is retained by the author(s), with first publication rights granted to the journal.

This is an open-access article distributed under the terms and conditions of the Creative Commons Attribution license (http://creativecommons.org/licenses/by/4.0/). 